\title{
The promotion of $\mathrm{CO}$ dissociation by molybdenum oxide overlayers on rhodium
}

\author{
Imre Szenti, László Bugyi*, Zoltán Kónya \\ MTA-SZTE Reaction Kinetics and Surface Chemistry Research Group, Department of Applied and Environmental Chemistry, University of Szeged, Rerrich \\ Béla sqr. 1, 6720 Szeged, Hungary
}

\begin{abstract}
A B S T R A C T
A considerable promotional effect of $\mathrm{MoO}_{\mathrm{x}}$ species observed at high pressures on the catalytic activity of rhodium initiated the present UHV model study. The $\mathrm{MoO}_{\mathrm{x}}$ overlayers formed on Rh films (0.15-20.0 ML) supported by $\mathrm{TiO}_{2}(110)$ substrate were characterized by AES, TPD, work function (WF) measurements and CO adsorption. On the mixed oxide support produced by depositing $1.2 \mathrm{ML}$ Mo onto $\mathrm{TiO}_{2}(110)$, a new recombinative $\mathrm{CO}$ desorption state was observed with $\mathrm{T}_{\mathrm{p}}=700 \mathrm{~K}$, assigned as $\beta$-CO and related to the promotional effect of $\mathrm{MoO}_{\mathrm{x}}$ species diffused onto Rh particles of $1.0 \mathrm{ML}$ coverage. The development of $\beta$-CO needs 0.5-0.7 ML threshold Rh coverage, attributable to particle size effect and geometric factors governing the $\mathrm{CO}$ adsorption. The $\beta$-CO state with $\mathrm{T}_{\mathrm{p}}=725-742 \mathrm{~K}$ could also be detected on $\mathrm{Rh}$ films covered by $\mathrm{MoO}_{\mathrm{x}}$ moiety formed by the oxidation of Mo overlayers in $\mathrm{O}_{2}$. Remarkably, recombinative $\mathrm{CO}$ desorption with $\mathrm{T}_{\mathrm{p}}=700 \mathrm{~K}$ could be observed on the $\mathrm{Rh}$ nanoparticles covered by $\mathrm{MoO}_{\mathrm{z}} \mathrm{C}_{\mathrm{y}}$ produced from pure Mo deposits by $\mathrm{CO}$ adsorption, too. In harmony with the promotional effect of $\mathrm{MoO}_{\mathrm{x}}$ overlayer found at high pressures, it is established that the dissociation of $\mathrm{CO}$ is maximal at 0.2-0.3 ML Mo coverage, attributed to the presence of active sites at the oxidemetal interface. The low desorption peak temperature $(700 \mathrm{~K})$ of associative $\mathrm{CO}$ desorption observed in the presence of $\mathrm{MoO}_{\mathrm{x}}$ and $\mathrm{MoO}_{\mathrm{z}} \mathrm{C}_{\mathrm{y}}$ overlayers indicates a low activation energy for the reactions of $\mathrm{O}_{\mathrm{a}}$ and $\mathrm{C}_{\mathrm{a}}$ atoms, allowing high reaction rates for these intermediates. The $\mathrm{MoO}_{\mathrm{x}}$ species exerted both promotion and inhibition effects on CO adsorption at sub-monolayer coverages, but above $1 \mathrm{ML}$ it completely suppressed the reactivity of rhodium layers towards $\mathrm{CO}$, suggesting that its surface concentration is a critical factor.
\end{abstract}

\section{Introduction}

The shortage of platinum metals capable of catalyzing several industrially important reactions induces great efforts in the scientific community to make their application more efficient and more economical. It was recognized long ago that the catalytic performance of important, but rather expensive rhodium metal can be influenced advantageously by different additives, including molybdenum and its oxides [1]. Metal oxides are mostly involved in heterogeneous catalysis inherently since they are widely used to support the finely dispersed, catalytically active metal particles. Moreover, it turned out that the socalled reducible oxide supports, like $\mathrm{MoO}_{\mathrm{x}}[1], \mathrm{TiO}_{\mathrm{x}}[2,3], \mathrm{FeO}_{\mathrm{x}}[4]$, etc., from which oxide particles can migrate onto the surface of metal nanoclusters, can act as promotors. Iron oxide in the form of encapsulation layer was found to exert promotional effect on the $\mathrm{CO}$ oxidation over a Pt catalyst [4]. It has been established by high pressure investigations that the rate of an industrially important reaction, the hydrogenation of $\mathrm{CO}$ is maximal at intermediate $\mathrm{TiO}_{\mathrm{x}}$ coverages [5]. In harmony with this, we verified in a UHV model study that the extent of $\mathrm{CO}$ dissociation is also maximal at the same coverage range [6]. Besides the promotion of $\mathrm{CO}$ hydrogenation on $\mathrm{Rh}$ catalysts by $\mathrm{MoO}_{\mathrm{x}}$ [1], molybdenum oxides were found to facilitate other reactions on different metals as well. The catalytic activity of $\mathrm{Pt} / \mathrm{Al}_{2} \mathrm{O}_{3}$ catalyst in propane oxidation reaction significantly increased in the presence of molybdenum and tungsten oxide additives, accompanied by excellent thermal stability of the modified catalyst [7]. Remarkably, a considerable catalytic promotional effect of different reducible oxides, like $\mathrm{MoO}_{\mathrm{x}}, \mathrm{TiO}_{\mathrm{x}}$ and $\mathrm{CeO}_{\mathrm{x}}$ has been reported for the rather inert $\mathrm{Au}(111)$ surface [8] in the water gas shift (WGS) reaction. $\mathrm{MoO}_{2}$ supported $\mathrm{Au}$ and $\mathrm{Cu}$ particles showed also outstanding activity in the WGS reaction and it was suggested that the oxide support was directly involved in the WGS process [9]. $\mathrm{MoO}_{\mathrm{x}}$-promoted $\mathrm{Au} / \mathrm{SiO}_{2}$ catalysts were found to be more active in reverse water-gas shift reaction (RWGS) by an order of magnitude than the un-promoted ones [10].

Some UHV model studies on the catalytic effect of molybdenum additives have also been performed. It was reported that on the Pt(111)

\footnotetext{
* Corresponding author.

E-mail address: sir@chem.u-szeged.hu (L. Bugyi).
} 
surface, oxidized Mo deposits blocked the Pt surface sites leaving essentially unchanged the adsorption behavior of $\mathrm{CO}$ on the uncovered part of platinum [11], but in a high-pressure study it was suggested that at the $\mathrm{Rh}-\mathrm{MoO}_{\mathrm{x}}$ interface $\mathrm{CO}$ can be bonded through its $\mathrm{C}$ atom to the $\mathrm{Rh}$ and via its $\mathrm{O}$ atom to $\mathrm{MoO}_{\mathrm{x}}$ [12]. It seems obvious that the more reduced is the $\mathrm{MoO}_{\mathrm{x}}$ species, corresponding to lowering in $\mathrm{x}$, the higher is its activity towards carbon monoxide and oxygen. As an extremity, a Mo-covered Pt(110) single crystal can be much more reactive than the bare or $\mathrm{MoO}_{\mathrm{x}}$-covered one $[13,14]$. The effect of a pure Mo overlayer on the reactivity of the supporting metal can hardly be established, since molybdenum mostly interacts with the reaction mixture. The reaction of Mo with oxidative reactants can occur even if it is covered completely by monolayer thick platinum metals [15]. Hence, as a result of the high affinity of Mo towards oxygen and due to the low surface free energy of the forming $\mathrm{MoO}_{\mathrm{x}}$ species, under oxidation conditions the end product of a bimetallic platinum metal-molybdenum system can be a platinum metal covered by $\mathrm{MoO}_{\mathrm{x}}$, irrespective of the deposition sequence of platinum metal and molybdenum. Depending on the oxidative or reductive nature of reaction mixture, the molybdenum can be present with variable oxidation states and may show complex redox properties. It has been reported that the oxidation state of Mo in an additive and the surface composition of Mo-Rh catalyst nanoparticles can be changed considerably in oxidative and reductive gases [16]. Consequently, it is desirable to carry out experiments with well-defined molybdenum oxides to elucidate the mechanism of their catalytic promotion. UHV model studies on $\mathrm{MoO}_{\mathrm{x}}$ modified $\mathrm{Rh}$ catalysts can eliminate several variables being present in real catalysis, making possible to identify the important factors influencing the catalyst activity and stability.

The hydrogenation of carbon monoxide on $\mathrm{Rh}$ was found to be greatly promoted in the presence of molybdenum oxide [12], and the experimental data suggested a mechanism including enhanced $\mathrm{CO}$ dissociation. It has been reported that the Mo:Rh content must be 0.6 for the sake of optimal hydrogenation activity of amides [17]. For the promotion of WGS reaction on Pt, the Mo:Pt ratio had to be less than 0.7 [18], and a complete deactivation of Pt sites for CO hydrogenation was found at higher Mo load [12]. In harmony with these findings, in our previous model study we found that the reactivity of $\mathrm{MoO}_{2}$ and $\mathrm{MoO}_{3}$ supported $\mathrm{Rh}$ particles $(0.4 \mathrm{ML})$ towards $\mathrm{CO}$ was completely suppressed after an annealing to $600 \mathrm{~K}$ due to $\mathrm{MoO}_{\mathrm{x}}$ migration to the rhodium [19]. To adjust finely the surface concentration of $\mathrm{MoO}_{\mathbf{x}}$ species, two methods are applied in the present work. First, selfassembled $\mathrm{MoO}_{\mathrm{x}}$ overlayers are formed on $\mathrm{Rh}$ particles supported by mixed titanium molybdenum oxides by heat treatments. The redox reactions between molybdenum deposits and $\mathrm{TiO}_{2}(110)$ substrate, surveyed in details in the literature [20], provide reliable recipes for producing mixed metal oxides. Second, $\mathrm{MoO}_{\mathrm{x}}$ is produced by the oxidation of Mo overlayers in $\mathrm{O}_{2}$ gas. As outlined above, molybdenum additives on $\mathrm{Rh}$ are expected to exert a catalytic promotional effect on $\mathrm{CO}$ dissociation, however, in our previous study $\mathrm{MoO}_{\mathrm{x}}$ originating form $\mathrm{MoO}_{2}$ and $\mathrm{MoO}_{3}$ supports was only found to inhibit the $\mathrm{CO}$ adsorption [19]. In the present work we extend the former investigations to a $\mathrm{MoO}_{\mathrm{x}}-\mathrm{Rh}$ system capable of promoting the decomposition of $\mathrm{CO}$.

\section{Experimental}

The experiments were performed in an ultrahigh vacuum (UHV) chamber (base pressure $<5 \times 10^{-8} \mathrm{~Pa}$ ) equipped with facilities for Auger electron spectroscopy (AES), and temperature programmed desorption (TPD). AES measurements were performed with a Physical Electronics coaxial-gun single pass cylindrical mirror analyzer (CMA), while mass spectrometric and TPD data were collected by a Balzers QMS 200 quadrupole mass spectrometer. A smooth polynomial was subtracted from each TPD spectrum as a baseline correction, applied also by others [21] and care was taken to avoid the generation of any additional TPD feature by this procedure. AES was performed in the differential mode with $3 \mathrm{keV}$ primary electron energy, $3 \mathrm{~V}$ modulation, and $1-2 \mu \mathrm{A}$ beam current. AES data were evaluated either plotting the absolute peak-to-peak heights of main peaks (Mo: $186 \mathrm{eV}$, Rh: $302 \mathrm{eV}$, Ti: $387 \mathrm{eV}$, O: $503 \mathrm{eV}, \mathrm{C}: 272 \mathrm{eV}$ ) or Auger ratios calculated from these peaks. Work function (WF) was measured by two methods. First, it was determined by recording the cut-off energy of inelastic secondary electrons excited by the AES beam. The sample bias was $-19 \mathrm{~V}$ and the relative WF values were derived by an accuracy of around $0.1 \mathrm{eV}$ comparing the positions of the inflexion points in the current vs. voltage curves [22] with that for the nearly stoichiometric $\mathrm{TiO}_{2}(110)$ surface. Second, sensitive non-contact WF measurements were performed in a temperature-programmed manner [23] by a Besocke type Kelvin-probe with a sensitivity of $1 \mathrm{meV}$.

The $\mathrm{TiO}_{2}$ (110) single-crystal was the product of PI-KEM. The sample was attached to a Ta plate with an oxide glue (Aremco, Ceramabond 571), and could be heated with a W filament placed behind the Ta plate. The sample temperature was measured by a chromel-alumel thermocouple, attached to the side of the sample with the same adhesive material. To avoid the fracture of titania single crystal, the heating and cooling rates during cleaning and all measurements presented here were always less than $2 \mathrm{~K} / \mathrm{s}$, regulated by a computer-controlled circuit. The duration of annealing in stepwise heating experiments was equal to or less than $1 \mathrm{~min}$.

The typical cleaning procedure of titania consisted of $\mathrm{Ar}^{+}$-ion bombardment $\left(1.5 \mathrm{keV}, 1 \times 10^{-7} \mathrm{~A} \mathrm{~cm}^{-2}, 300 \mathrm{~K}, 30 \mathrm{~min}\right)$ and annealing at $1000 \mathrm{~K}$ for $30 \mathrm{~min}$. The absence of oxygen-treatments resulted in blue-colored, defective crystal. Note, that after this procedure the contribution of $\mathrm{Ti}^{3+}$ and $\mathrm{Ti}^{2+}$ signals to the $\mathrm{Ti} 2 \mathrm{p}$ photoemission feature was found to be below $3 \%$, according to XPS measurements performed in another vacuum chamber. The above treatment ensured the appropriate electrical conductivity for electron spectroscopy and high enough defect-density to observe 2D-like growth of Rh-particles in extended coverage range, which allowed the estimation of surface coverage through AES measurements [24]. 1 monolayer (ML) Rh coverage corresponds to a Rh surface concentration, where, supposing a 2D film growth on a $\mathrm{TiO}_{2}(110)$ single-crystal, the Rh LEIS signal would disappear [25]. This method was verified by AES measurements, through following the growth of Rh layer on Mo multilayer which is known to obey a layer-by-layer growth mode [26], giving a well-defined break-point in the Mo AES signal intensity at $1 \mathrm{ML}$ Rh coverage. It is known from previous STM investigations that the above sample treatment results basically in $(1 \times 1)$ bulk terminated registry, although the presence of $1-2 \%$ of defect sites (0D dots and $1 \mathrm{D}$ strings of $\mathrm{Ti}_{2} \mathrm{O}_{3}$ stoichiometry) cannot be excluded [27]. This surface is mentioned throughout this article as a nearly stoichiometric titania and is designated as s- $\mathrm{TiO}_{2}(110)$.

An EGN4 e-beam evaporator of Oxford Applied Research was used for the deposition of Rh and Mo by physical vapor deposition (PVD) at a sample temperature of $300-330 \mathrm{~K}$. The oxidation of molybdenum layers (0.1-1.2 ML) was performed via reaction with the titania support, or by heating in $1 \times 10^{-6} \mathrm{mbar}_{2}$ for $20 \mathrm{~min}$ at 560 or $650 \mathrm{~K}$.

\section{Results and discussion}

\subsection{Properties of Rh particles supported by mixed molybdenum- titanium oxide}

In our former study it was verified by LEIS measurements that the extent of thermally assisted encapsulation of 1.0 ML thick Rh film was somewhat modified by 1.2 ML Mo pre-deposited onto the $\mathrm{TiO}_{2}(110)$ substrate [28]. Since it has been found that the $\mathrm{TiO}_{\mathrm{x}}$ species migrated to the $\mathrm{Rh}$ promotes the dissociation of adsorbed $\mathrm{CO}[2,6]$, to clarify the promotional effect of $\mathrm{MoO}_{\mathrm{x}}$ overlayer, the extent of encapsulation of $\mathrm{Rh}$ by $\mathrm{MoO}_{\mathrm{x}}$ and $\mathrm{TiO}_{\mathrm{x}}$ species on the Mo pre-covered titania is to be estimated. For comparison with previous LEIS data [28], the effect of heating on the surface composition of a $1.0 \mathrm{ML}$ thick $\mathrm{Rh}$ layer 


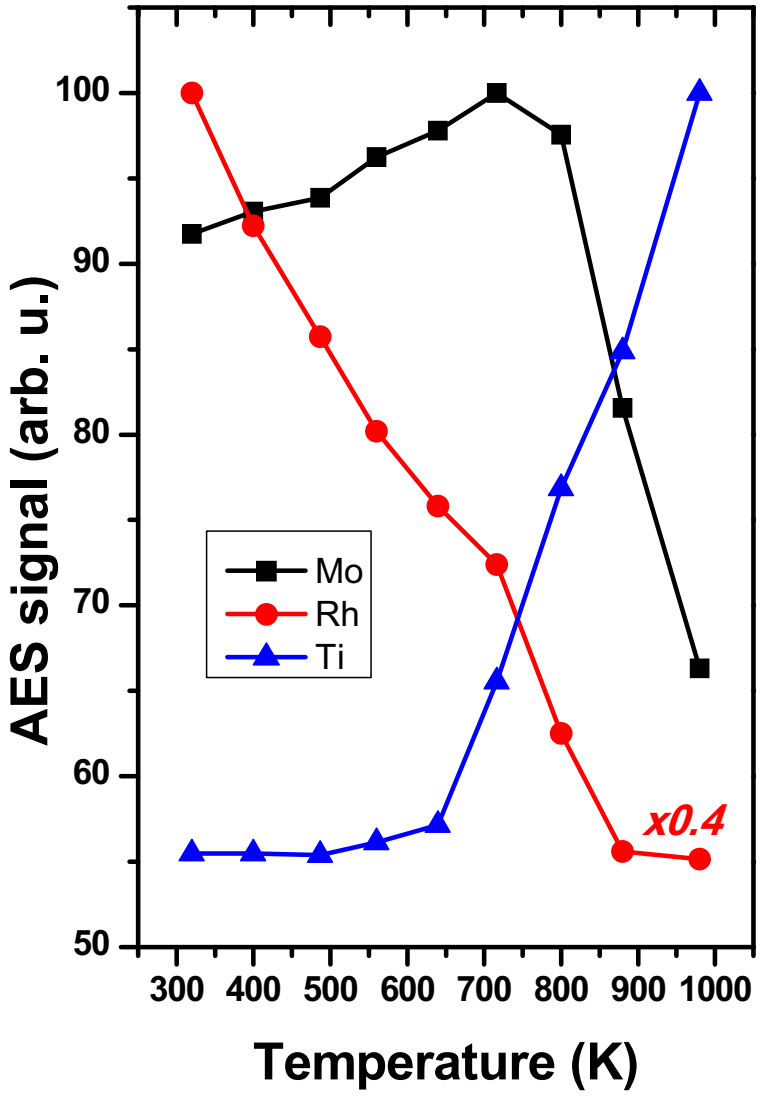

Fig. 1. Mo, Rh and Ti AES signal intensities as a function of temperature for a $\mathrm{TiO}_{2}(110)$ crystal covered by 1.2 ML Mo and 1.0 ML Rh.

deposited on the titania, pre-covered with 1.2 ML Mo was followed by AES, see Fig. 1. On annealing to $720 \mathrm{~K}$, the Rh AES signal reduced by about $30 \%$, and both the Mo and Ti signals enhanced, which can be explained by the encapsulation of $\mathrm{Rh}$ particles by $\mathrm{MoO}_{\mathrm{x}}$ and $\mathrm{TiO}_{\mathrm{x}}$ species, completing by about $700 \mathrm{~K}$ as proven by the disappearance of $\mathrm{Rh}$ LEIS signal shown in a previous study [28]. Although Rh clusters (0.4 ML) on a $\mathrm{TiO}_{2}(110)$ support do not aggregate up to $700 \mathrm{~K}$ [29], this cannot be completely ruled out for the particles supported by the Mo-covered titania, giving a possible contribution to the Mo AES signal enhancement (Fig. 1). Above $720 \mathrm{~K}$, the decay in Rh AES peak intensity accompanied by the Ti signal enhancement can partly be due to the aggregation of Rh particles. The decrease in Mo AES signal above $720 \mathrm{~K}$ can be attributed to an extended oxidation of Mo-deposit to $\mathrm{MoO}_{2}$ and $\mathrm{MoO}_{3}$ through redox reaction with the substrate and above $800 \mathrm{~K}$ to the sublimation of $\mathrm{MoO}_{3}$ to the gas phase [30]. It was found in an earlier study that above $500 \mathrm{~K}$ the outermost surface region loses Mo [28]. The decay in surface Mo concentration on annealing at $500-1000 \mathrm{~K}$ is accompanied by a $0.75 \mathrm{eV}$ decrease in WF (not shown), which can also be correlated with the diffusion of Mo into the defect sites of titania lattice and with the sublimation of $\mathrm{MoO}_{\mathrm{x}}$ species. Considering the lower $\mathrm{WF}$ of $\mathrm{TiO}_{\mathrm{x}}$ overlayer [31], $0.6 \mathrm{eV}$, as compared with that of $\mathrm{MoO}_{\mathrm{x}}$ [19], $1.0 \mathrm{eV}$, the WF decrease above $500 \mathrm{~K}$ can be related to the increase of $\mathrm{TiO}_{\mathrm{x}}$ coverage on $\mathrm{Rh}$ particles at the expense of $\mathrm{MoO}_{\mathrm{x}}$ species.

To reveal the details of the surface chemistry of Rh particles (1.0 ML) supported by the Mo covered (1.2 ML) titania, the effect of stepwise heating was followed by CO titration, as presented in Fig. $2 \boldsymbol{A}$. Note that CO does not desorb from the Rh-free, Mo-covered titania surface after $20.0 \mathrm{~L}$ of $\mathrm{CO}$ exposure. The molecular $\mathrm{a}$-CO desorption characterized with $\mathrm{T}_{\mathrm{p}}=460$ and $570 \mathrm{~K}$ is suppressed after pre-annealing to 480 and $630 \mathrm{~K}$, while a new state, designated as $\beta-\mathrm{CO}$, showing broad feature at $700 \mathrm{~K}$ without pre-annealing, appears and is shifted to
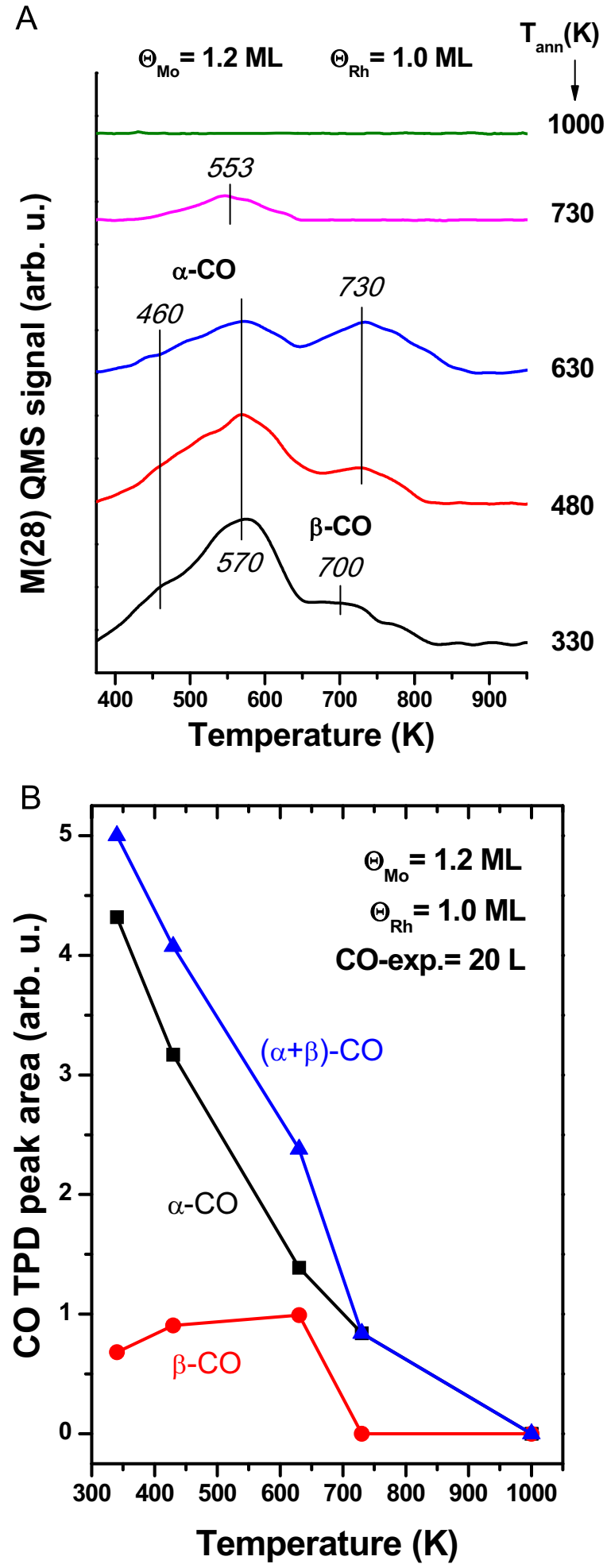

Fig. 2. (A) CO desorption from the $\mathrm{s}-\mathrm{TiO}_{2}(110)+1.2 \mathrm{ML} \mathrm{Mo}+1.0 \mathrm{ML}$ Rh surface preannealed to the indicated temperatures and exposed to $20.0 \mathrm{~L}$ of $\mathrm{CO}$ at $300 \mathrm{~K}$. (B) Desorption peak areas for the molecular and recombinative CO states as a function of pre-annealing temperature. Lines serve as guide to the eyes.

$730 \mathrm{~K}$. The $\beta$-CO state developed with $\mathrm{T}_{\mathrm{p}}=700 \mathrm{~K}$ can be associated with a recombinative $\mathrm{CO}$ desorption affected by the $\mathrm{MoO}_{\mathrm{x}}$ surface species, which was found to migrate easily to the Rh particles from the $\mathrm{MoO}_{2}$ and $\mathrm{MoO}_{3}$ supports between 330 and $600 \mathrm{~K}$ [19]. After pre-annealing to $630 \mathrm{~K}$, the $\beta$-CO peak became asymmetric and a shoulder appeared at around $770 \mathrm{~K}$. A comparison with former findings reveals that the 


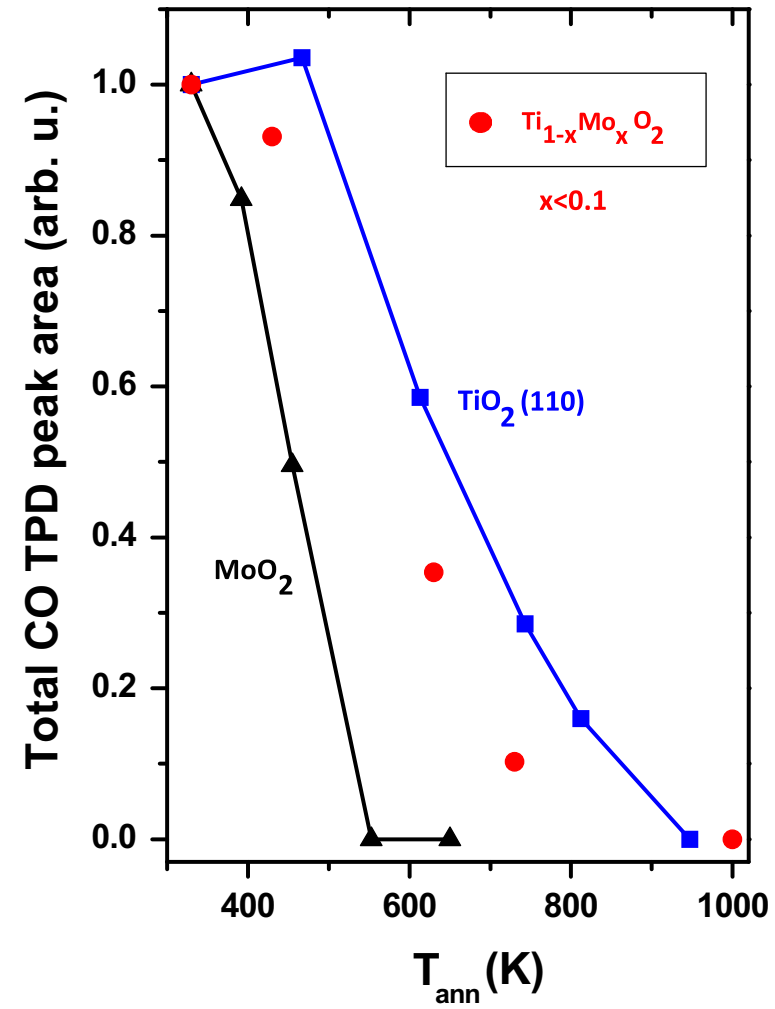

Fig. 3. Normalized total amounts of desorbed $\mathrm{CO}$ from the $\mathrm{MoO}_{2}, \mathrm{TiO}_{2}$ and $\mathrm{TiO}_{1-\mathrm{x}} \mathrm{Mo}_{\mathrm{x}} \mathrm{O}_{2}$ surfaces covered by $0.4 \mathrm{ML} \mathrm{Rh}$, pre-annealed to different temperatures and saturated with $20.0 \mathrm{~L}$ of $\mathrm{CO}$ at $300 \mathrm{~K}$.

broadening of this feature may be the consequence of some $\mathrm{TiO}_{\mathrm{x}}$ migration to the $\mathrm{Rh}$ particles, which is known to generate a recombinative $\gamma$-CO state with $\mathrm{T}_{\mathrm{p}}=765 \mathrm{~K}$ [6]. After pre-annealing to $730 \mathrm{~K}$, the desorption states above $650 \mathrm{~K}$ are completely eliminated. Further annealing to $1000 \mathrm{~K}$ removed all the $\mathrm{CO}$ desorption features, which is in agreement with a former observation regarding the inhibition effect of a continuous, pure $\mathrm{TiO}_{\mathrm{x}}$ layer on $\mathrm{CO}$ adsorption [6]. The quantitative evaluation of $\mathrm{CO}$ desorption is presented in Fig. $2 \boldsymbol{B}$, where it is illustrated again that the $\beta$-CO state evolved already at $330 \mathrm{~K}$, reflecting that $\mathrm{MoO}_{\mathrm{x}}$ can migrate to the $\mathrm{Rh}$ particles at this temperature. In Fig. 3, comparison of the normalized total amounts of desorbed $\mathrm{CO}$ (Fig. 2) with that from $\mathrm{TiO}_{2}$ and $\mathrm{MoO}_{2}$ supported $\mathrm{Rh}$ particles [19] reveals that on the Mo covered titania (designated as $\mathrm{Ti}_{1-\mathrm{x}} \mathrm{Mo}_{\mathrm{x}} \mathrm{O}_{2}$, see the reasoning below) the amount of desorbed $\mathrm{CO}$ up to $720 \mathrm{~K}$ preannealing temperature is between those found for the pure oxides. For $\mathrm{Rh}$ nanoparticles supported by $\mathrm{MoO}_{2}$ the $\mathrm{CO}$ desorption ceases after pre-annealing to $550 \mathrm{~K}$ due to the migration of a rather mobile and inactive $\mathrm{MoO}_{\mathrm{x}}$ species onto the metal [19]. The above findings support that the species which cover the Rh supported by the mixed titanium molybdenum oxide have an apparent intermediate mobility between that of $\mathrm{TiO}_{\mathrm{x}}$ and $\mathrm{MoO}_{\mathrm{x}}$. Up to $550 \mathrm{~K}$ mostly $\mathrm{MoO}_{\mathrm{x}}$ may cover the surface and above $550 \mathrm{~K}$ the surface concentration of $\mathrm{TiO}_{\mathrm{x}}$ can be enhanced.

The formation of mixed molybdenum-titanium oxide following the deposition of 1.2 ML Mo on the $\mathrm{TiO}_{2}(110)$ substrate can be inferred from literature findings. It is established that in the interfacial reaction of $\mathrm{Mo}$ and $\mathrm{TiO}_{2}(110)$ surface a maximum oxidation state of +4 can be reached in a molybdenum deposit at $300 \mathrm{~K}$ [30]. The similarity between the structure of rutile $\mathrm{TiO}_{2}$ and monoclinic $\mathrm{MoO}_{2}$ allows a limited mixing (5-6\%) of these oxides, while at higher concentrations of $\mathrm{MoO}_{2}$ phase separation occurs [21]. Following the decomposition of $\mathrm{Mo}(\mathrm{CO})_{6}$ and a subsequent heat treatment at $853 \mathrm{~K}$ in air, the formation of a substitutional near-surface alloy with a stoichiometry of $\mathrm{Ti}_{1-\mathrm{x}} \mathrm{Mo}_{\mathrm{x}} \mathrm{O}_{2}(\mathrm{x}<0.1)$ was found [32], corresponding to $\mathrm{Mo}^{4+}$ ions embedded in the titania lattice. Although the replacement of $\mathrm{Ti}^{4+}$ ions with $\mathrm{Mo}^{4+}$ ions needs thermal treatment [21,32], the WF changes of the Mo-covered $\mathrm{TiO}_{2}(110)$ sample [19] indicate that it occurs to some extent even at $420 \mathrm{~K}$. Accordingly, the surface composition of support during stepwise heating (Figs. 2 and 3) can be assigned as $\mathrm{Ti}_{1-\mathrm{x}} \mathrm{Mo}_{\mathrm{x}} \mathrm{O}_{2}$ with the remark that $\mathrm{x}$ is increasing during the heating process.

Taking into account the desorption peak temperatures for the recombinative $\mathrm{CO}$ states shown in $\mathbf{F i g} . \mathbf{2 A}$, it is reasonable to suppose that from the $\mathrm{Ti}_{1-\mathrm{x}} \mathrm{Mo}_{\mathrm{x}} \mathrm{O}_{2}$ mixed oxide below $500 \mathrm{~K}$ mostly $\mathrm{MoO}_{\mathrm{x}}$ migrates to the $\mathrm{Rh}$, but above this temperature the overlayer formed is composed of mixed $\mathrm{MoO}_{\mathrm{x}}$ and $\mathrm{TiO}_{\mathrm{x}}$ layer. It is remarkable that the promotional effect for $\mathrm{CO}$ dissociation on the mixed oxide support is maximized at lower pre-annealing temperature, $630 \mathrm{~K}$ (Fig. 2), as on the titania-supported $\mathrm{Rh}$ particles, $700 \mathrm{~K}$ [6]). This can be explained with the higher mobility of $\mathrm{MoO}_{\mathrm{x}}$ species originating from the mixed molybdenum titanium oxide as compared with that of $\mathrm{TiO}_{\mathrm{x}}$ stemming from $\mathrm{TiO}_{2}$ (110). Importantly, the recombinative $\mathrm{CO}$ desorption occurs with lower desorption peak temperature in the presence of $\mathrm{MoO}_{\mathrm{x}}$ (700 K, Fig. 2) than under the influence of $\mathrm{TiO}_{\mathrm{x}}(765 \mathrm{~K},[6])$, meaning that in a catalytic reaction the removal of surface $\mathrm{O}$ and $\mathrm{C}$ atoms takes place with lower activation energy, allowing higher reaction rate.

To investigate the effect of temperature on the mobility of $\mathrm{MoO}_{\mathrm{x}}$ species originating from the mixed molybdenum titanium oxide, on the Mo covered (1.2 ML) titania $1 \mathrm{ML}$ thick Rh layer was also formed at $200 \mathrm{~K}$ (not shown). It is known from XPS data that the extent of redox reaction between titania and Mo at this low temperature is the same as at $300 \mathrm{~K}$ [28], hence the production of similar $\mathrm{MoO}_{\mathrm{x}}$ species can be expected in both cases. A $\mathrm{CO}$ adsorption-desorption experiment revealed that on the layer produced at $200 \mathrm{~K}$ no recombinative $\beta$-CO state formed, verifying that at this temperature $\mathrm{MoO}_{\mathrm{x}}$ species could not migrate onto the $\mathrm{Rh}$ particles.

It is to be considered that the dissociation of $\mathrm{CO}$ on titania supported $\mathrm{Rh}$ particles was found to occur only above a threshold $\mathrm{Rh}$ coverage, $\sim 0.2$ ML [24], what can be related with coverage dependent structural and electronic features characteristic of the metal deposit and with metal substrate interaction [33]. To reveal a possible particle size effect, the influence of $\mathrm{Rh}$ coverage on the decomposition of adsorbed $\mathrm{CO}$ was investigated on the Mo-covered titania support. In Fig. 4 it can be seen that at 1.2 ML Mo pre-coverage two molecular CO states populate, with $\mathrm{T}_{\mathrm{p}} \sim 420 \mathrm{~K}$ and with $\mathrm{T}_{\mathrm{p}}=493 \mathrm{~K}$. The apparent upward shift in the peak temperature of the latter one above 0.5 ML Rh coverage can partly be due to overlapping with the broad $\beta$-CO feature appearing at around $700 \mathrm{~K}$. The formation of $\beta$-CO state begins only at a threshold coverage range, $\Theta_{\mathrm{Rh}}=0.5-0.7 \mathrm{ML}$. To explain this phenomenon it must be considered that the $\mathrm{CO}$ dissociation activity of $\mathrm{Rh}$ particles has been found to be correlated with the availability of highly coordinated adsorption sites which depends on the size and shape of nanoparticles [34]. For CO dissociation an ensemble of metal atoms in a particular geometry capable of binding the $\mathrm{CO}$ molecule and its dissociation products can be an important factor [35]. In other words, to bind the $\mathrm{O}$ and $\mathrm{C}$ adatoms, a minimum number of $\mathrm{Rh}$ atoms are needed in the $\mathrm{Rh}$ particles. It was found that the $\mathrm{CO}$ dissociation activity of alumina supported $\mathrm{Rh}$ particles depended on the island size, exhibiting a maximum for islands with around 1000 atoms [33], which was correlated with the presence of highly coordinated adsorption centers on $\mathrm{Rh}$ particles, the formation of which requires obviously a minimum number $\mathrm{Rh}$ atoms. In addition, it is important to emphasize, that the electronic band structure, determining the chemical reactivity of metal deposits, also depends on the number of constituent atoms of metal particles [33]. These effects can contribute to the appearance of the threshold Rh coverage observable in Fig. 4, corresponding to an average $\mathrm{Rh}$ particle size below which the reactivity towards the $\mathrm{CO}$ molecule is suppressed even in the presence of a reactive $\mathrm{MoO}_{\mathrm{x}}$ moiety.

The surface processes were also followed by temperature-programmed WF measurements performed with a Kelvin-probe, see the inset in Fig. 4. This method which monitors around 7 square 


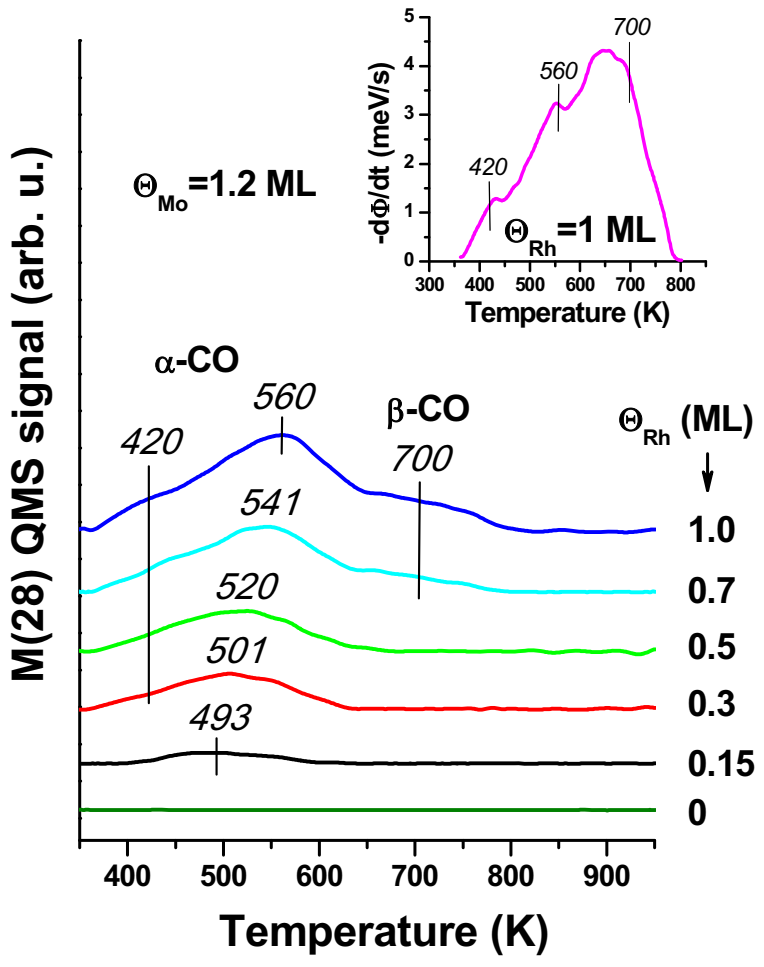

Fig. 4. CO TDS traces for different amounts of Rh deposited on the $\mathrm{TiO}_{2}(110)$ surface pre-covered by $1.2 \mathrm{ML}$ Mo and exposed to $20.0 \mathrm{~L}$ of $\mathrm{CO}$ at $300 \mathrm{~K}$. Inset: the negative derivative of the surface work function as a function of temperature, taken at the same heating rate and metal coverages as the uppermost TDS curve.

millimeter area in the middle of the sample, rules out the contribution of gas desorption from the back and edge of the sample to the WF signal, which, on the contrary, may exert some influence on the TPD spectra [36]. The molecular and recombinative $\mathrm{CO}$ desorption states could be detected by the Kelvin-probe also as overlapping features at 1.2 ML Mo pre-deposition and 1.0 ML Rh coverage. In comparison with the corresponding, uppermost TPD spectrum of Fig. 4, the amount of molecular state seems less than that of recombinative one. This can be associated with the dipole moment of adsorbed states [23]. Accordingly, the dissociation products, $\mathrm{O}$ and $\mathrm{C}$ adatoms seems to have a larger average dipole moment than the $\mathrm{CO}$ molecule. Note that good coincidence was found in the shape and location of normalized TPD spectra and the negative derivative of temperature-dependent WF signals on the surfaces where molecular CO desorption prevailed, i.e. on Rh multilayers.

3.2. The effect of oxidized and pure Mo overlayers on the reactivity of $R h$ nanoparticles towards $C O$

To suppress the possible contribution of $\mathrm{TiO}_{\mathrm{x}}$ overlayer on the surface chemistry of $\mathrm{TiO}_{2}(110)$ supported $\mathrm{Rh}$ nanoparticles, the effect of oxidized Mo overlayers on $\mathrm{CO}$ adsorption has also been addressed. In Fig. $5 \boldsymbol{A}$ it is demonstrated how the $\mathrm{MoO}_{\mathrm{x}}$ species produced from its elements on the top of $1.0 \mathrm{ML}$ thick Rh film influences the thermal desorption of CO. The Mo coverage varied between 0.1 and $0.5 \mathrm{ML}$, and the Mo deposits were oxidized in $10^{-6} \mathrm{mbar} \mathrm{O}_{2}$ for $20 \mathrm{~min}$ at $650 \mathrm{~K}$. A similar treatment of Mo multilayer resulted in the formation of molybdenum oxide with a high WF of $7.0 \mathrm{eV}$, attributed to $\mathrm{MoO}_{3}$ [19] and it was established that under similar conditions the oxidation number of Mo deposited on titania raised above +4 [30]. Note that a control thermal desorption spectroscopy (TDS) experiment verified that from the mixed molybdenum titanium oxide no $\mathrm{CO}$ desorption occurred following 20.0 L gas exposure. In Fig. 5 it can be seen that at 0.1 ML Mo coverage the $\mathrm{MoO}_{\mathrm{x}}$ suppressed the $\alpha$-CO states at $\mathrm{T}_{\mathrm{p}}=440$
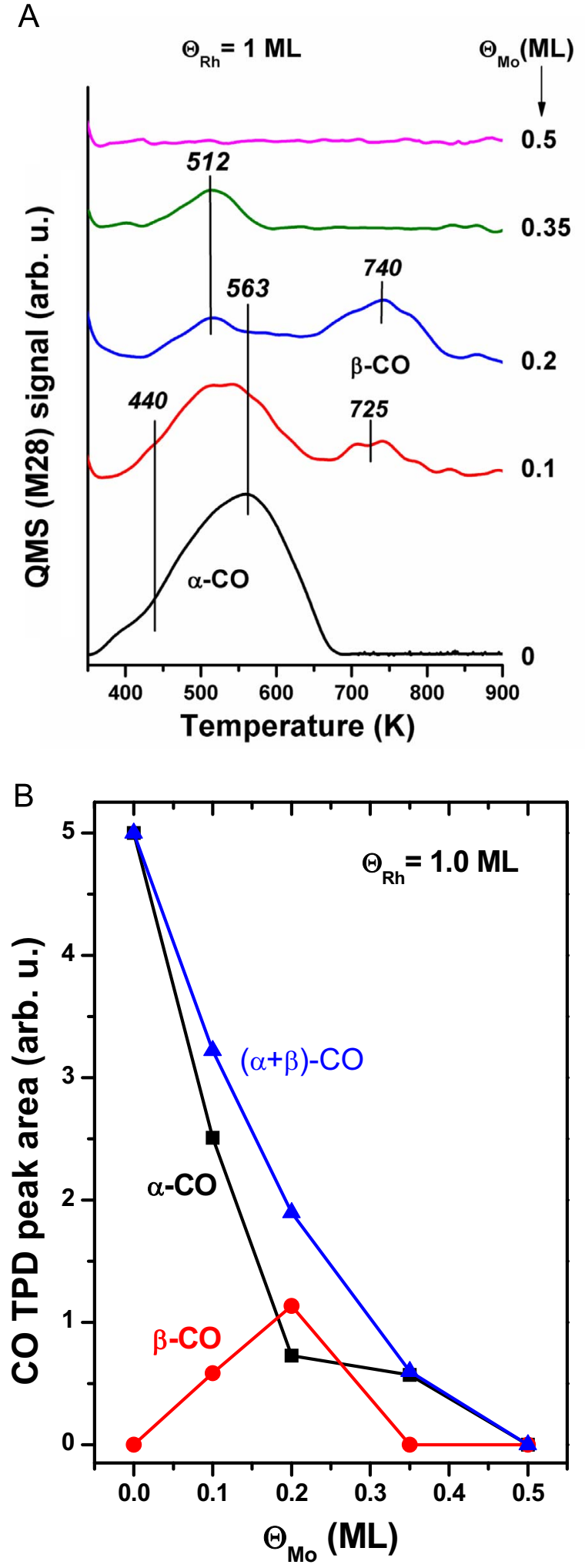

Fig. 5. (A) $\mathrm{CO}$ desorption from the $\mathrm{MoO}_{\mathrm{x}}$ covered $\mathrm{Rh}$ particles (1.0 ML) after exposing the surface to $20.0 \mathrm{~L}$ of $\mathrm{CO}$ at $300 \mathrm{~K} . \mathrm{MoO}_{\mathrm{x}}$ was formed by the oxidation of the Mo deposits at $560 \mathrm{~K}$ in $10^{-6} \mathrm{mbar}_{2}$ lasting for $20 \mathrm{~min}$. (B) The corresponding integrated peak areas for the molecular and recombinative $\mathrm{CO}$ states as a function of Mo coverage. Lines serve as guide to the eyes.

and $563 \mathrm{~K}$, but generated a new, broad $\mathrm{CO}$ desorption feature with $\mathrm{T}_{\mathrm{p}}=725 \mathrm{~K}$, which can be identified as the recombinative $\beta$-CO state. The state with $\mathrm{T}_{\mathrm{p}}=563 \mathrm{~K}$ can be ascribed to molecular $\mathrm{CO}$ adsorbed at ontop, while the one with $\mathrm{T}_{\mathrm{p}}=440 \mathrm{~K}$ at bridge position [24]. Repulsive 
adsorbate-adsorbate interaction can contribute to the broadening of TDS traces. At $\Theta_{\mathrm{Mo}}=0.2 \mathrm{ML}$ the $\alpha$-states are further reduced, the $\beta$-CO is intensified and its $\mathrm{T}_{\mathrm{p}}$ is shifted to $740 \mathrm{~K}$. At $\Theta_{\mathrm{Mo}}=0.35 \mathrm{ML}$ the $\beta-\mathrm{CO}$ is eliminated, but the $\alpha-\mathrm{CO}$ with $\mathrm{T}_{\mathrm{p}}=512 \mathrm{~K}$ is still present. The concerted suppression of $\alpha-C O$ states at $T_{p}=563 \mathrm{~K}$ and $T_{p}=440 \mathrm{~K}$ reflects the bonding of $\mathrm{MoO}_{\mathrm{x}}$ species on the corresponding adsorption centers with similar probabilities, resulting in a narrow TDS feature with $\mathrm{T}_{\mathrm{p}}=512 \mathrm{~K}$ at $0.35 \mathrm{ML}$ Mo coverage. At $\Theta_{\mathrm{Mo}}=0.50 \mathrm{ML}$ all $\mathrm{CO}$ desorption ceased, revealing a complete hindrance of $\mathrm{CO}$ adsorption. Although the size and shape of titania supported $\mathrm{Rh}$ nanoparticles was found unaltered by STM up to $700 \mathrm{~K}$ during the encapsulation with $\mathrm{TiO}_{\mathrm{x}}$ species [29], structural changes of $\mathrm{Rh}$ particles covered by $\mathrm{MoO}_{\mathrm{x}}$ cannot be ruled out on annealing. The determination of change in the particle size from $\mathrm{CO}$ desorption experiments is not straightforward, since different $\mathrm{CO}$ adsorption states develop which require different number of surface sites on Rh (Fig. 5A). However, it can be estimated that the size of Rh clusters is not changing substantially in the presence of $\mathrm{MoO}_{\mathrm{x}}$ overlayer and adsorbed $\mathrm{CO}$, since the total amount of desorbed $\mathrm{CO}$ as a function of $\mathrm{MoO}_{\mathrm{x}}$ coverage decreases approximately linearly (Fig. $5 \boldsymbol{B}$ ).

Clearly, in Fig. 5 the amount of dissociative $\beta-\mathrm{CO}$ state goes through maximum with the increase of the $\mathrm{MoO}_{\mathrm{x}}$ coverage, hence the formation of this state can be associated with the overall number of perimeter sites. The disappearance of the $\beta-\mathrm{CO}$ at $\Theta_{\mathrm{Mo}}=0.35 \mathrm{ML}$ can be due to the coalescence of $\mathrm{MoO}_{\mathrm{x}}$ species into larger islands resulting in a strong reduction in the number of active $\mathrm{MoO}_{\mathrm{x}}$ perimeter sites. If the coalesced islands are large enough, the concentration of $\beta$-CO drops below the detection limit of TDS, but a fraction of the surface may still remain free to allow molecular $\mathrm{CO}$ adsorption. Note that in $\mathbf{F i g} .2 \boldsymbol{A}$ the appearance of $\alpha-\mathrm{CO}$ following a thermal treatment at $730 \mathrm{~K}$ can be explained similarly, that is with the aggregation of $\mathrm{MoO}_{\mathrm{x}}$ and $\mathrm{TiO}_{\mathrm{x}}$ species, leaving enough adsorption centers for molecular $\mathrm{CO}$ bonding. It is important to note that the position of $\alpha$-CO desorption peaks varies only slightly with the $\mathrm{MoO}_{\mathrm{x}}$ coverage in Fig. $\mathbf{5 A}$, which is indicative of a weak interaction between $\mathrm{MoO}_{\mathrm{x}}$ overlayer and rhodium, allowing a simple site-blocking effect. This mechanism was also observed for a $\mathrm{MoO}_{\mathrm{x}}$ covered $\mathrm{Pt}(110)$ single crystal as deduced from $\mathrm{CO}$ adsorption experiments [14]. On the other hand, the appearance of recombinative $\beta$-CO state reflects the presence of reactive $\mathrm{MoO}_{\mathrm{x}}$ species on $\mathrm{Rh}$. Similarly, in a high pressure study [8] reactive $\mathrm{CeO}_{\mathrm{x}}, \mathrm{TiO}_{\mathrm{x}}$ and $\mathrm{MoO}_{\mathrm{x}}$ moieties were found to generate water dissociation even on the rather indifferent $\mathrm{Au}(111)$ single crystal.

To exclude any pre-annealing of the Mo-covered rhodium clusters before TPD experiments, the titania supported Rh films were covered by different amounts of Mo metal and their reactivity was tested through CO adsorption $(20.0 \mathrm{~L})$. In Fig. $\mathbf{6 A}$ it is demonstrated that enhancing the coverage of metallic Mo from $0.2 \mathrm{ML}$ to $1.0 \mathrm{ML}$ on a 1.0 ML thick Rh film strongly suppresses the amount of $\alpha$-CO state with $T_{p}=570 \mathrm{~K}$, but leaves nearly intact the other state with $T_{p} \sim 450 \mathrm{~K}$. The $\gamma$-CO with $\mathrm{T}_{\mathrm{p}}=885 \mathrm{~K}$ on the Mo-free titania originates from the titania-rhodium interface [24], and is eliminated at and above 0.2 ML Mo coverage. Noticeably, the $\beta-\mathrm{CO}$ with $\mathrm{T}_{\mathrm{p}}=700 \mathrm{~K}$ also appears on the Mo-covered Rh particles, and it is detectable even at $\Theta_{\mathrm{Mo}}=2.0 \mathrm{ML}$. Its amount has a maximum at $\Theta_{\mathrm{Mo}}=0.5 \mathrm{ML}$ (Fig. $6 \boldsymbol{B}$ ), suggesting that the recombination of $\mathrm{C}$ and $\mathrm{O}$ atoms proceeds at the molybdenum-rhodium interface. Considering the unvaried and low, $700 \mathrm{~K}$ peak temperature for the associative CO desorption at $0.2-2.0 \mathrm{ML}$ Mo coverages, it is reasonable to suppose that it originates not from the inner part of Mo islands, where the $\mathrm{O}$ and $\mathrm{C}$ atoms are more highly coordinated to Mo atoms, but from their perimeter sites where weaker binding occurs. If the $\mathrm{O}$ and $\mathrm{C}$ atom containing, 2.0 ML thick Mo layer forms 3D structures, the $\mathrm{MoO}_{\mathrm{z}} \mathrm{C}_{\mathrm{y}}-\mathrm{Rh}$ interface represents adsorption sites where the recombinative $\mathrm{CO}$ state can still be populated. Molecular $\mathrm{CO}$ desorption at this coverage may be absent if the 3D structures are produced only during the heating cycle of TPD experiment.

The question arises whether the $\mathrm{CO}$ dissociation could be observed on Mo-covered platinum metals in previous model studies. It has been
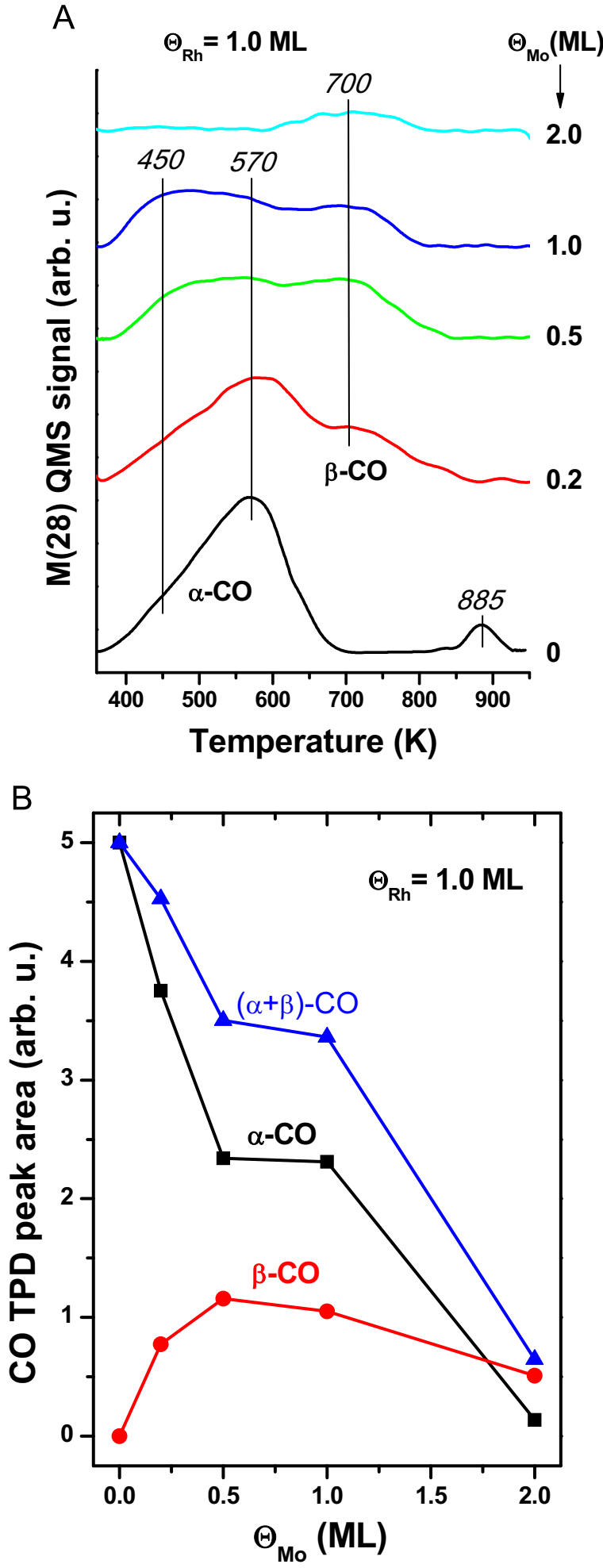

Fig. 6. (A) CO desorption from Rh particles (1.0 ML) covered by different amounts of Mo, after exposing the surface to $20.0 \mathrm{~L}$ of $\mathrm{CO}$ at $300 \mathrm{~K}$. (B) Integrated peak areas for the molecular $\alpha$-CO and dissociative $\beta$-CO states. Lines serve as guide to the eyes.

established that the oxidation state of molybdenum in a deposit can greatly influence the reactivity of a platinum metal [13]. As an extremity, a Pt(110) single crystal covered by metallic molybdenum is more reactive than the bare or $\mathrm{MoO}_{\mathrm{x}}$-covered one [14]. After exposing a $\mathrm{Pt}(110)$ crystal to $10.0 \mathrm{~L} \mathrm{Mo}(\mathrm{CO})_{6}$ at $100 \mathrm{~K}$ a CO TDS feature appearing at $540 \mathrm{~K}$ was associated with $\mathrm{CO}$ desorption from the Mo deposit [13]. In addition, $\mathrm{CO}$ desorption was detected with $\mathrm{T}_{\mathrm{p}}=575$ 
and $600 \mathrm{~K}$ after saturating the $\mathrm{Pt}(110)$ and $\mathrm{Pt}(110)+\mathrm{MoO}_{\mathrm{x}}$ surfaces with $\mathrm{Mo}(\mathrm{CO})_{6}$. Since the latter peak temperatures are by more than $100 \mathrm{~K}$ higher than the $\mathrm{T}_{\mathrm{p}} \mathrm{s}$ of molecular $\mathrm{CO}$ desorption for either $\mathrm{Pt}$ [13] or Mo [37] surfaces, the corresponding desorption states can be attributed to the recombination of $\mathrm{C}$ and $\mathrm{O}$ adatoms. Furthermore, AES proved that the surface $\mathrm{C}$ and $\mathrm{O}$ contaminants originating from the high temperature $(700 \mathrm{~K})$ decomposition of $\mathrm{Mo}(\mathrm{CO})_{6}$ on the same Pt(110) surface could be completely eliminated by annealing to $1000 \mathrm{~K}$ [14]. These observations indicate that on a Mo-covered Pt(110) surface $\mathrm{C}$ and $\mathrm{O}$ atoms recombine above $500 \mathrm{~K}$ and below $1000 \mathrm{~K}$, that is in the same temperature region, where associative $\mathrm{CO}$ desorption was found from the $\mathrm{CO}$-saturated $\mathrm{Rh}+\mathrm{Mo}$ and $\mathrm{Rh}+\mathrm{MoO}_{\mathrm{x}}$ surfaces. Accordingly, on different platinum metals the surface species produced by the oxidation of molybdenum deposits with the oxygen of dissociated $\mathrm{CO}$, seems to have the potential to act as promotor in those catalytic reactions where the decomposition of $\mathrm{CO}$ is an intermediate step.

It is worth comparing the TDS data for CO desorption from $\mathrm{MoO}_{\mathrm{x}}$ and Mo covered Rh surfaces, displayed in Fig. 5 and Fig. 6. First, it is to be considered that the $\mathrm{MoO}_{\mathrm{x}}$ particles are reactive with $\mathrm{CO}$ only at their perimeter [11], [12], while the whole surface of Mo islands covering the $\mathrm{Rh}$ can react with $\mathrm{CO}$. As a result, the inactive $\mathrm{MoO}_{\mathrm{x}}$ layer [14] can completely suppress the reactivity of Rh towards CO adsorption at 0.5 ML Mo coverage that is the $\mathrm{MoO}_{\mathrm{x}}$ species prepared can fully block the surface. On the contrary, the $2.0 \mathrm{ML}$ thick Mo layer reacting with $\mathrm{CO}$ seems to be able to produce 3D structures, providing active reaction centers at the rhodium-molybdenum interface. It is remarkable that the temperature range for recombinative $\mathrm{CO}$ desorption is $800-1200 \mathrm{~K}$ on a macroscopic molybdenum surface [37], but from the perimeter of the nanosized, Rh supported Mo particles CO desorbs with $\mathrm{T}_{\mathrm{p}}=700 \mathrm{~K}$. This low temperature can be explained by the influence of the underlying rhodium and by the lowered coordination of surface Mo, $\mathrm{C}$ and $\mathrm{O}$ atoms to each other as compared with that in a 3D structure. Taking into account that on the Mo layer supported by Rh particles the $\mathrm{CO}$ adsorption results in $\mathrm{O}$ and $\mathrm{C}$-atoms, on the one hand it is straightforward that the oxidation number of Mo cannot be 0 following $\mathrm{CO}$ exposures. On the other hand, the oxidation number of Mo must be lower than that reached by extensive oxidation in $\mathrm{O}_{2}$ gas. Accordingly, Mo with oxidation number less than +6 is responsible for the promotional effect of $\mathrm{MoO}_{\mathrm{z}} \mathrm{C}_{\mathrm{y}}$ particles on $\mathrm{CO}$ dissociation.

3.3. The impact of $\mathrm{MoO}_{\mathrm{x}}$ species on the surface chemistry of $\mathrm{CO}$ on $\mathrm{Ar}^{+}$-ion sputtered $\mathrm{Rh}$ multilayers

To eliminate completely the effect of $\mathrm{TiO}_{2}(110)$ support on the surface chemistry of $\mathrm{Rh}, \mathrm{MoO}_{\mathrm{x}}$ species was produced on $\mathrm{Rh}$ multilayers. To get rid of the trace amount of carbon being present in $\mathrm{Rh}$ multilayers after metal deposition, they were annealed to $1000 \mathrm{~K}$ to encapsulate them by $\mathrm{TiO}_{\mathrm{x}}$, which oxidized the carbon contamination. The $\mathrm{TiO}_{\mathrm{x}}$ overlayer was removed by mild $\mathrm{Ar}^{+}$-ion sputtering [6] and the clean $\mathrm{Rh}$ was covered by Mo and oxidized in $\mathrm{O}_{2}$ stream at $560 \mathrm{~K}$.

In Fig. 7 the effect of annealing on the 20.0 ML thick Rh multilayer covered by $\mathrm{MoO}_{\mathrm{x}}$ is displayed, as followed by AES and WF measurements. The points at $300 \mathrm{~K}$ correspond to a $1.0 \mathrm{ML}$ thick Mo deposit. The oxidation performed at $560 \mathrm{~K}$ caused a small change in the Mo/Rh AES ratio, but was accompanied by a significant WF enhancement of $1.3 \mathrm{eV}$. The stepwise heating between 560 and $1000 \mathrm{~K}$ resulted in the gradual decrease of both the Mo/Rh AES ratio and WF. Remarkably, the former quantity indicated a nearly complete loss of Mo in the nearsurface region after annealing at $1000 \mathrm{~K}$. This is in harmony with the evaporation of volatile $\mathrm{MoO}_{3}$ species above $800 \mathrm{~K}$ [30]. The elimination of $\mathrm{MoO}_{\mathrm{x}}$ from the surface is accompanied by $1.1 \mathrm{eV}$ WF decrease. A similar value, $1.0 \mathrm{eV}$ was calculated for $\mathrm{MoO}_{\mathrm{x}}$ species covering completely a $0.4 \mathrm{ML}$ thick, $\mathrm{MoO}_{3}$-supported $\mathrm{Rh}$ layer after annealing to $550 \mathrm{~K}$ [19], suggesting that the two species are similar. The high initial WF difference presented in Fig. $7,2.0 \mathrm{eV}$, related to the WF of nearly stoichiometric titania involves a high absolute WF of around $7.0 \mathrm{eV}$,

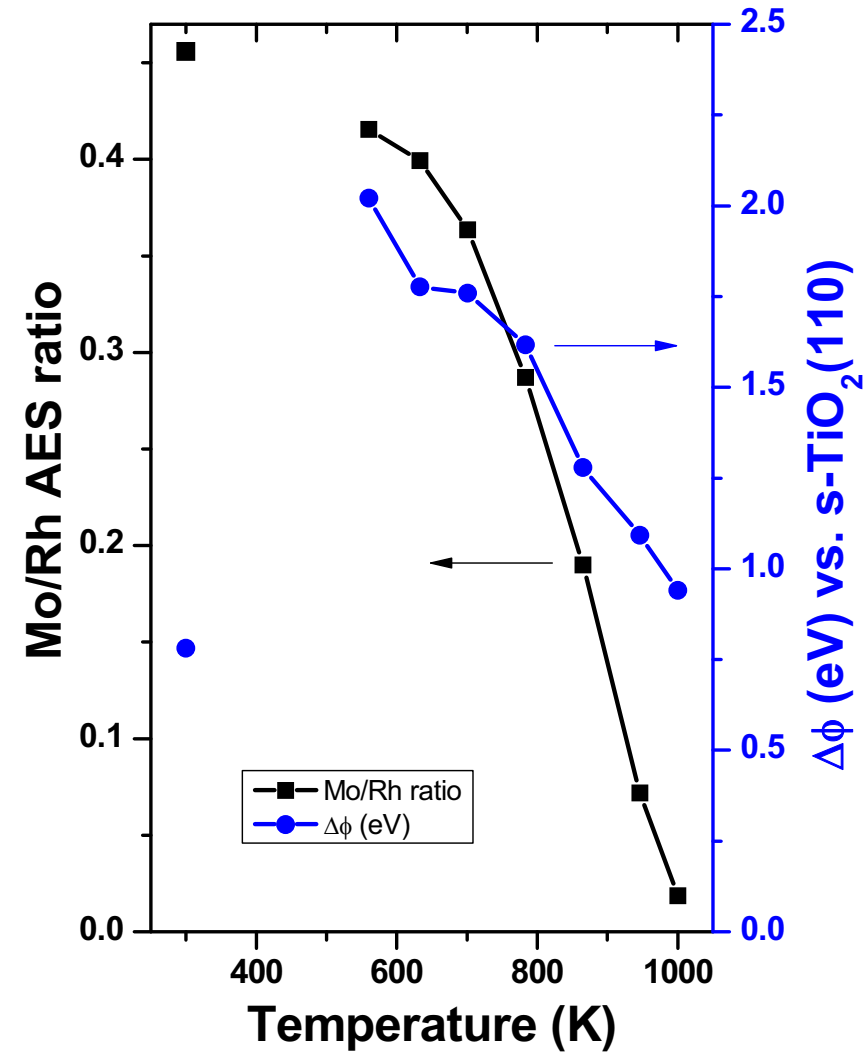

Fig. 7. The effect of annealing on the Mo/Rh AES ratio and work function of $\mathrm{MoO}_{x}$ covered, $20 \mathrm{ML}$ thick Rh multilayer. The Mo coverage was $1.0 \mathrm{ML}$, and the oxidation process consisted of $20 \mathrm{~min}$ annealing in $10^{-6} \mathrm{mbar}_{2}$ at $560 \mathrm{~K}$. The points at $300 \mathrm{~K}$ belong to the Mo-covered Rh prior to oxidation.

which is close to that of bulk $\mathrm{MoO}_{3}$ [19]. High dipole moments were also found for atomically thin $\mathrm{MoO}_{\mathrm{x}}$ layers formed on graphene [38]. The question arises, how the thickness of $\mathrm{MoO}_{\mathrm{x}}$ overlayer correlates with its WF. Well-defined $\mathrm{MoO}_{3}$ films could be prepared on the $\mathrm{Au}(111)$ surface with monolayer [39] and bilayer thickness [40]. It was established that the charge transfer between a molybdenum trioxide monolayer and the supporting metal can result in the reduction of molybdenum ions, corresponding to lower WF of the $\mathrm{MoO}_{3}$ overlayer as compared with that of bulk oxide [41]. The WF was found to depend on the $\mathrm{MoO}_{\mathrm{x}}$ layer thickness, being higher at higher oxide coverages. Since our $\mathrm{MoO}_{\mathrm{x}}$ overlayer is characterized, as shown in Fig. 7 , by a WF of near to $7.0 \mathrm{eV}$, a value close to that of bulk $\mathrm{MoO}_{3}$, it is probably composed of a bilayer.

In Fig. $8 \mathrm{CO}$ desorption signals are presented for $\mathrm{MoO}_{\mathrm{x}}$ covered $\mathrm{Rh}$ multilayers saturated with $\mathrm{CO}$ at $300 \mathrm{~K}$. It is demonstrated that increasing the coverage of $\mathrm{MoO}_{\mathrm{x}}$ species, the $\mathrm{T}_{\mathrm{p}}$ of the associative $\mathrm{CO}$ desorption ( $\gamma-\mathrm{CO}, 812 \mathrm{~K}$ ), characteristic of the ion-sputtered $\mathrm{Rh}$ film [6], decreases gradually, manifesting in the appearance of a broad TPD feature with $\mathrm{T}_{\mathrm{p}}=785 \mathrm{~K}$ at $\Theta_{\mathrm{Mo}}=0.2 \mathrm{ML}$. At higher molybdenum coverages, $\Theta_{\mathrm{Mo}}=0.5 \mathrm{ML}$ and $\Theta_{\mathrm{Mo}}=0.75 \mathrm{ML}$ the recombinative CO desorption is characterized by peaks at $\mathrm{T}_{\mathrm{p}}=742 \mathrm{~K}$. Overlapping molecular CO desorption states show TDS features peaked at 588 and $540 \mathrm{~K}$, which are suppressed with the enhancement of $\mathrm{MoO}_{\mathrm{x}}$ concentration. The development of $\beta$-CO with $\mathrm{T}_{\mathrm{p}}=742 \mathrm{~K}$ can be attributed to the same process that was observed for Rh particles covered by $\mathrm{MoO}_{\mathrm{x}}$ produced from 0.1-0.2 ML Mo (Fig. 5), namely to the $\mathrm{MoO}_{\mathrm{x}}$ assisted dissociation of $\mathrm{CO}$. The enhanced peak temperature for the recombinative $\mathrm{CO}$ desorption, $742 \mathrm{~K}$, as compared with $725 \mathrm{~K}$ observed for Rh particles (Fig. 5A) can be due to the presence of defect sites generated by $\mathrm{Ar}^{+}-$ ion sputtering. Noticeably, the recombinative CO-desorption from a pure Mo multilayer (not shown) provides a much higher desorption 

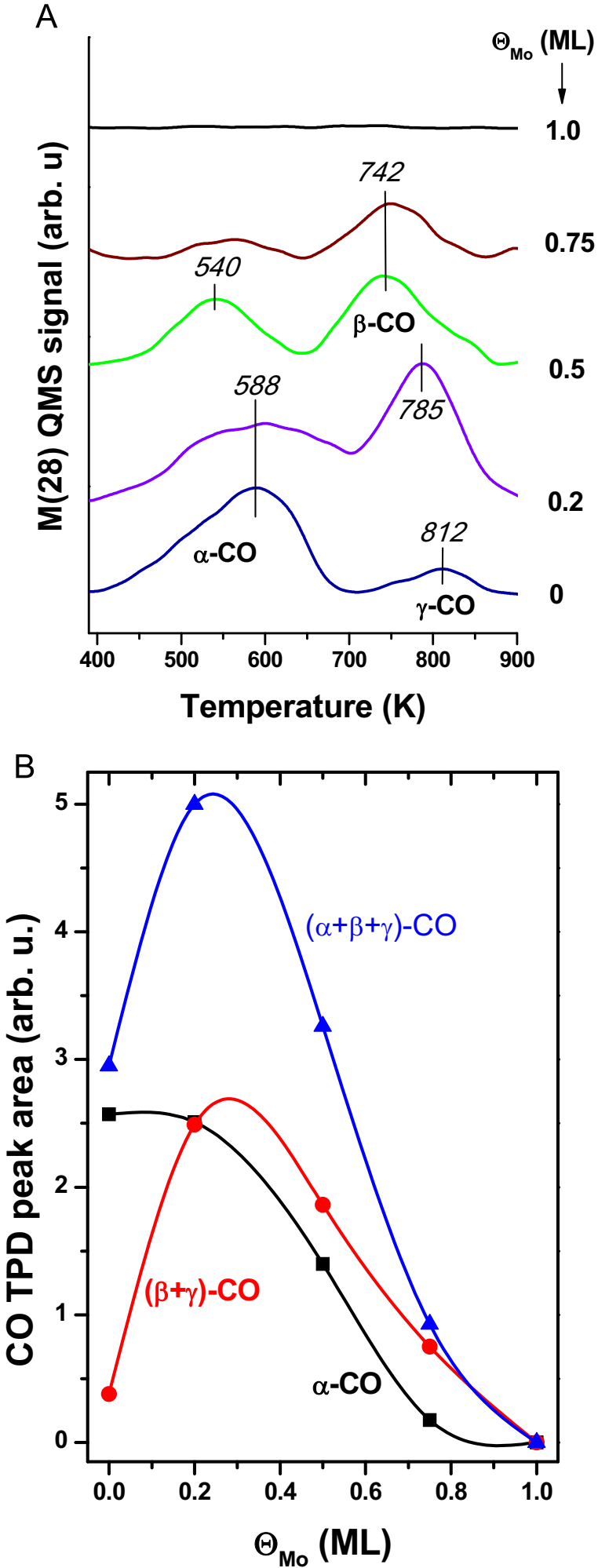

Fig. 8. (A) $\mathrm{CO}$ desorption traces for $\mathrm{Ar}^{+}$-ion sputtered, $20 \mathrm{ML}$ thick $\mathrm{Rh}$ multilayers covered by different amounts of $\mathrm{MoO}_{\mathrm{x}}$ and saturated with $20.0 \mathrm{~L}$ of $\mathrm{CO}$ at $300 \mathrm{~K}$. $\mathrm{MoO}_{\mathrm{x}}$ was prepared by the oxidation of Mo deposits in $10^{-6} \mathrm{mbar}_{2}$ at $560 \mathrm{~K}$ lasting for 20 min. (B) Molecular, recombinative and total CO desorption peak areas as a function of Mo coverage.

peak temperature, $950 \mathrm{~K}$. Considering that in the presence of a $0.5 \mathrm{ML}$ thick oxidized Mo overlayer the TDS peak characteristic of associative CO desorption is located at $742 \mathrm{~K}$, that is at much lower temperature than on rhodium, $812 \mathrm{~K}$, and on a molybdenum single crystal, 950 and $1050 \mathrm{~K}$ [37], it can be established that on a defect-rich Rh surface the
$\mathrm{MoO}_{\mathrm{x}}$ species promotes the decomposition of carbon monoxide. The extent of promotion is maximal at intermediate, 0.2-0.3 ML Mo coverage as shown in $\mathbf{F i g} . \mathbf{8 B}$, similar to that presented in Fig. $5 \boldsymbol{B}$ for Rh nanoparticles, suggesting that the active sites for CO dissociation are located at the $\mathrm{Rh}-\mathrm{MoO}_{\mathrm{x}}$ interface on both surfaces.

As illustrated in Fig. 8, for a Rh multilayer covered by $\mathrm{MoO}_{\mathrm{x}}$ produced from 1.0 ML Mo and exposed to $20.0 \mathrm{~L} \mathrm{CO}$, any $\mathrm{CO}$ desorption is completely missing. Regarding the blocking effect of $\mathrm{MoO}_{\mathrm{x}}$ species on $\mathrm{CO}$ adsorption, this observation is in harmony with our former finding [19] and with those for the $\mathrm{Pt}(111)$ [11] and $\mathrm{Pt}(110)$ [14] single crystals, supporting that a continuous $\mathrm{MoO}_{\mathrm{x}}$ overlayer suppresses the reactivity of platinum metals towards carbon monoxide. Noticeably, the $0.75-1.0$ ML Mo coverage range (Fig. 8), where the $\mathrm{CO}$ adsorption is completely suppressed on the ion-sputtered $\mathrm{Rh}$ film, is about twice as much as that for the Rh nanoparticles (Fig. 5). This can be explained by the preferential growth of $3 \mathrm{D} \mathrm{MoO}_{\mathrm{x}}$ particles in the atomic scale valleys of the ion-sputtered surface, which makes possible a hindered aggregation of $\mathrm{MoO}_{\mathrm{x}}$ particles at $0.75 \mathrm{ML}$ Mo coverage and the formation of $\beta-\mathrm{CO}$ at their perimeter sites.

The question arises what might be the oxidation number of molybdenum in the $\mathrm{MoO}_{\mathrm{x}}$ species being active in $\mathrm{CO}$ dissociation. The characterization of ultrathin $\mathrm{MoO}_{\mathrm{x}}$ layers has been addressed by XPS on several substrates. On graphene, $\mathrm{Mo}^{5+}$ and $\mathrm{Mo}^{6+}$ ions were detected for a $0.15 \mathrm{~nm}$ thick $\mathrm{MoO}_{3}$ layer, but $\mathrm{Mo}^{6+}$ ions prevailed at $15 \mathrm{~nm}$ film thickness [38], suggesting a thickness effect. The activity of $\mathrm{Au} / \mathrm{SiO}_{2}$ catalysts in RWGS reaction increased by an order of magnitude as a result of promotion by $\mathrm{MoO}_{\mathrm{x}}$, in which Mo was found to be in +6 oxidation state [10]. $\mathrm{MoO}_{2}$ supported $\mathrm{Au}$ and $\mathrm{Cu}$ particles showed outstanding activity in the WGS reaction and it was suggested that the oxide support, containing $\mathrm{Mo}^{4+}$ ions was directly involved in the WGS process [9]. A monolayer thick $\mathrm{MoO}_{\mathrm{x}}$ species was found to be reducible by extended heat treatment on $\mathrm{Au}(111)$ [39], resulting in a stable composition containing $50 \% \mathrm{Mo}^{5+}$ and $50 \% \mathrm{Mo}^{6+}$ through the formation of extended 1D shear defects. According to the above findings and to a former suggestion that the $\mathrm{CO}$ molecule binds to the Rh supported oxide islands through a reduced metal center [12], it is reasonable to suppose that to exert a promotional effect, oxygen vacancies at the perimeter of oxide particles are needed where Mo ions with oxidation number less than the maximal +6 for Mo are present.

The present UHV study confirms the suggestion of former high pressure work regarding the promotion of $\mathrm{CO}$ dissociation by $\mathrm{MoO}_{\mathrm{x}}$ species on $\mathrm{Rh}$ particles [12]. Clearly, the $\mathrm{MoO}_{\mathrm{x}}$ overlayer is capable to generate recombinative $\beta$-CO state both on $\mathrm{Rh}$ nanoparticles and argon-ion sputtered Rh films. It has been proven that to observe the promotional influence of $\mathrm{MoO}_{\mathrm{x}}$ overlayers on $\mathrm{CO}$ dissociation the $\mathrm{Rh}$ coverage must exceed a threshold coverage of 0.5-0.7 ML. Accordingly, at the 0.4 ML Rh coverage applied in our previous work [19] the promotion of $\mathrm{CO}$ decomposition was not observed. In harmony with the finding of high pressure studies that to promote maximally the hydrogenation reaction of $\mathrm{CO}$ [3], [5], the reducible oxide nanoparticles must be present on the Rh nanoparticles at intermediate submonolayer coverages, it is established that the optimal $\mathrm{MoO}_{\mathrm{x}}$ concentration for $\mathrm{CO}$ decomposition corresponds to $0.2-0.3 \mathrm{ML}$ Mo coverage (Figs. $5 \boldsymbol{B}$ and $8 \boldsymbol{B}$ ), supporting that the active centers are located at the $\mathrm{Rh}-\mathrm{MoO}_{\mathrm{x}}$ interface. The lowered peak temperature of recombinative $\mathrm{CO}$ desorption for the $\mathrm{MoO}_{\mathrm{x}}$ modified rhodium nanoparticles, $700 \mathrm{~K}$, as compared with that for the $\mathrm{TiO}_{\mathrm{x}}$-covered ones, $765 \mathrm{~K}$ [6], includes that the $\mathrm{C}$ and $\mathrm{O}$ atoms generated by $\mathrm{CO}$ dissociation are bonded less strongly to the surface in the presence of $\mathrm{MoO}_{\mathrm{x}}$ species. During the catalytic hydrogenation of $\mathrm{CO}$, at the perimeter of promotor oxide species the metal ions must pass through oxidation-reduction cycles [12]. The reduction of oxide overlayer proceeding through a reaction with adsorbed $\mathrm{C}$ atoms has lower activation energy if the $\mathrm{CO}$ desorption peak temperature is lower, predicting an easier reduction with hydrogen adatoms as well. According to the well-known volcano curve confirmed for many heterogeneous catalytic reactions, for optimal 
catalytic activity the reaction intermediates must bind to the catalyst not too strongly and not too weakly [42], which seems to be valid for the $\mathrm{C}$ and $\mathrm{O}$ atoms on the $\mathrm{MoO}_{\mathrm{x}}$ promoted rhodium surfaces, allowing high reaction rates in their further reactions.

Due to its low surface free energy and high surface mobility, the $\mathrm{MoO}_{\mathrm{x}}$ species wets rhodium well, and for this reason on $\mathrm{MoO}_{2}$ and $\mathrm{MoO}_{3}$ supported $\mathrm{Rh}$ particles the $\mathrm{CO}$ adsorption was found to be completely blocked by the $\mathrm{MoO}_{\mathrm{x}}$ overlayer at relatively moderate temperature, $600 \mathrm{~K}$ [19]. In the present study, the elimination of $\mathrm{CO}$ adsorption by $\mathrm{MoO}_{\mathrm{x}}$ species was also observed at $\Theta_{\mathrm{Mo}}=0.5 \mathrm{ML}$ on $\mathrm{Rh}$ nanoparticles and $\Theta_{\mathrm{Mo}}=1.0 \mathrm{ML}$ on the $\mathrm{Ar}^{+}$- ion sputtered $\mathrm{Rh}$ multilayers, respectively, pointing again to the necessity of low enough Mo/ $\mathrm{Rh}$ mass ratio in a catalyst to avoid a complete inhibition effect.

\section{Conclusions}

i) Diffusion of $\mathrm{MoO}_{\mathrm{x}}$ and $\mathrm{TiO}_{\mathrm{x}}$ species from a Mo-covered (1 ML) titania to supported $\mathrm{Rh}$ particles (1 ML) at $330-1000 \mathrm{~K}$ was confirmed by AES and CO titration experiments.

ii) The $\mathrm{MoO}_{\mathrm{x}}$ overlayer on a $1 \mathrm{ML}$ thick $\mathrm{Rh}$ film generated a new recombinative $\mathrm{CO}$ desorption state with $\mathrm{T}_{\mathrm{p}}=700 \mathrm{~K}$, assigned as $\beta$ CO.

iii) On a Mo pre-covered (1.2 ML) $\mathrm{TiO}_{2}(110)$ surface the development of $\beta$-CO needs $0.5-0.7 \mathrm{ML}$ threshold Rh coverage, attributable to $\mathrm{Rh}$ particle size effect and geometric factors governing the $\mathrm{CO}$ adsorption.

iv) The $\beta$-CO state can also be formed on 1.0 and 20.0 ML thick Rh films covered by $\mathrm{MoO}_{\mathrm{x}}$ species prepared by the oxidation of Mo overlayers in $\mathrm{O}_{2}$ and on $\mathrm{Rh}$ nanoparticles covered by $\mathrm{MoO}_{\mathrm{z}} \mathrm{C}_{\mathrm{y}}$ species produced from pure Mo deposits by $\mathrm{CO}$ adsorption.

v) The amount of $\beta$-CO was maximized at $0.2-0.3$ ML Mo coverage, supporting that it formed at the $\mathrm{MoO}_{\mathrm{x}}-\mathrm{Rh}$ interface, and that this sate is associated with the enhanced reactivity for CO hydrogenation found in high pressure studies. $\mathrm{MoO}_{\mathrm{x}}$ hindered the molecular $\mathrm{CO}$ adsorption, underlining that the amount of this additive must be low for catalytic promotion.

vi) The low peak temperature $(700 \mathrm{~K})$ for the associative $\mathrm{CO}$ desorption on the $\mathrm{MoO}_{\mathrm{x}}$ and $\mathrm{MoO}_{\mathrm{z}} \mathrm{C}_{\mathrm{y}}$ modified $\mathrm{Rh}$ particles corresponds to a low activation energy in the recombination reaction of $\mathrm{O}_{\mathrm{a}}$ and $\mathrm{C}_{\mathrm{a}}$ atoms, which allows high reaction rates for these intermediates.

\section{Acknowledgement}

Supports through grants of the Hungarian Scientific Research Fund (OTKA) K120115, GINOP-2.3.2-15-2016-00013 and COST Action CM1104 are gratefully acknowledged.

\section{References}

[1] E.E. Lowenthal, L.F. Allard, M. Te, H.C. Foley, J. Mol. Catal. A-Chem. 100 (1995)
129.

[2] D.N. Belton, Y.-M. Sun, J.M. White, J. Catal. 102 (1986) 338-347.

[3] A. Boffa, C. Lin, A.T. Bell, G.A. Somorjai, J. Catal. 149 (1994) 149.

[4] M. Lewandowski, Y.N. Sun, Z.-H. Qin, S. Shaikhutdinov, H.-J. Freund, Appl. Catal. A: Gen. 391 (2011) 407-410.

[5] K. Hayek, M. Fuchs, B. Klötzer, W. Reichl, G. Rupprechter, Top. Catal. 13 (2000) 55.

[6] L. Bugyi, I. Szenti, Z. Kónya, Appl. Surf. Sci. 313 (2014) 432.

[7] Y. Men, G. Kolb, R. Zapf, H. Pennemann, V. Hesse, Chem. Eng. Res. Des. 87 (2009) 91-96.

[8] J.A. Rodriguez, S. Ma, P. Liu, J. Hrbek, J. Evans, M. Pérez, Science 318 (2007) 1757.

[9] J.A. Rodriguez, P. Liu, J. Hrbek, M. Perez, J. Evans, J. Mol. Catal. A: Chem. 281 (2008) 59-65.

[10] R. Carrasquillo-Flores, I. Ro, M.D. Kumbhalkar, S. Burt, C.A. Carrero, A.C. AlbaRubio, J.T. Miller, I. Hermans, G.W. Huber, George, J.A. Dumesic, J. Am. Chem. Soc. 137 (2015) 10317-10325.

[11] A.M. Robinson, M.M. Montemore, S.A. Tenney, P. Sutter, J.W. Medlin, J. Phys. Chem. C 117 (2013) 26716.

[12] B.J. Kip, E.G.F. Hermans, J.H.M.C. Van Wolput, N.M.A. Hermans, J. Van Grondelle, R. Prins, Appl. Catal. 35 (1987) 109-139.

[13] Z. Jiang, L. Xu, W. Huang, J. Mol. Catal. A: Chem. 304 (2009) 16-21.

[14] Z. Jiang, W. Huang, H. Zhao, Z. Zhang, D. Tan, X. Bao, J. Mol. Catal. A: Chem. 268 (2007) 213-220

[15] W. Tang, G. Henkelman, J. Phys. Chem. C 130 (2009) 194504.

[16] D.A. Storm, F.P. Mertens, M.C. Cataldo, E.C. Decanio, J. Catal. 141 (1993) $478-485$.

[17] G. Beamson, A.J. Papworth, C. Philipps, A.M. Smith, R. Whyman, J. Catal. 269 (2010) 93-102.

[18] W.D. Williams, L. Bollmann, J.T. Miller, W.N. Delgassa, F.H. Ribeiro, Appl. Catal. B: Environ. 125 (2012) 206.

[19] I. Szenti, L. Bugyi, Z. Kónya, Surf. Sci. 641 (2015) 60-67.

[20] Q. Fu, T. Wagner, Surf. Sci. Rep. 62 (2007) 431-498.

[21] O. Karshoglu, X. Song, H. Kuhlenbeck, H.-J. Freund, Top. Catal. 56 (2013) 1389-1403.

[22] L.J. Whitman, W. Ho, J. Chem. Phys, 89 (1981) 7621.

[23] T. Livneh, Y. Lilach, M. Asscher, J. Chem. Phys. 111 (1999) 11138.

[24] L. Bugyi, R. Németh, Surf. Sci. 605 (2011) 808.

[25] L. Óvári, L. Bugyi, Z. Majzik, A. Berkó, J. Kiss, J. Phys. Chem. C 112 (2008) $18011-18016$.

[26] L.Q. Jiang, M. Strongin, Phys. Rev. B 42 (1990) 3292.

[27] A. Berkó, A. Magony, J. Szökő, Langmuir 21 (2005) 4562.

[28] L. Bugyi, L. Óvári, J. Kiss, Surf. Sci. 603 (2009) 2958-2963.

[29] A. Berkó, G. Ménesi, F. Solymosi, Surf. Sci. 372 (1997) 202.

[30] V. Blondeau-Patissier, B. Domenichini, A. Steinbrunn, S. Bourgeois, Appl. Surf. Sci. 175-176 (2001) 674-677.

[31] L. Bugyi, L. Óvári, Z. Kónya, Appl. Surf. Sci. 280 (2013) 60-66.

[32] G.A. Rizzi, A.E. Reeder, S. Agnoli, G. Granozzi, Surf. Sci. 600 (2006) 3345.

[33] M. Baumer, H.-J. Freund, Prog. Surf. Sci. 61 (1999) 127-198.

[34] S. Andersson, M. Frank, A. Sandell, A. Giertz, B. Brena, P.A. Bruhwiler, N. Martensson, J. Libuda, M. Baumer, H.-J. Freund, J. Chem. Phys. 108 (1998) 2967.

[35] M. Che, C.O. Bennett, Adv Catal. 20 (1989) 153.

[36] J.M. Heitzinger, S.C. Gebhard, B.E. Koel, Surf. Sci. 275 (1992) 209-222.

[37] S. Raaen, X. Yu, Appl. Surf. Sci. 349 (2015) 17-20.

[38] J. Meyer, P.R. Kidambi, B.C. Bayer, C. Weijtens, A. Kuhn, A. Centeno, A. Pesquera, A. Zurutuza, J. Robertson, S. Hofmann, Sci. Rep. 4 (2014) 1.

[39] X. Deng, S.Y. Quek, M.M. Biener, J. Biener, D.H. Kanga, R. Schalek, E. Kaxiras, C.M. Friend, Surf. Sci. 602 (2008) 1166-1174.

[40] S. Guimond, D. Gobke, J.M. Sturm, Y. Romanyshyn, H. Kuhlenbeck, M. Cavalleri, H.-J. Freund, J. Phys. Chem. C 117 (2013) 8746.

[41] M.T. Greiner, L. Chai, M.G. Helander, W.-M. Tang, Z.-H. Lu, Adv. Funct. Mater. 23 (2013) 215-226.

[42] J.K. Norskov, T. Bligaard, J. Rossmeisl, C.H. Christensen, Nat. Chem. 1 (2009) 37. 